\title{
Clinical, radiographic, diagnostic and cephalometric features of pycnodysostosis in comparison with Turkish cephalometric norms: A case report
}

\author{
Hasan Kamak' \\ Gulen Kamak² \\ ibrahim Yavuz
}

\section{ABSTRACT}

Pycnodysostosis is a rare genetic disorder and was first described in 1962 by Maroteaux and Lamy. The incidence of this anomaly is estimated to be 1.7 per 1 million births. The principal characteristics of this disorder are short stature, prominent eyes with blue sclera, beaked nose, cranial dysplasia, exposed fontanelles and cranial sutures, clavicular dysplasia, total/partial dysplasia of the terminal phalanges, obtused mandibular gonial angle, and generally increased bone density. Some features of pycnodysostosis are similar to osteopetrosis and cleidocranial dysostosis. Therefore, it must be distinguished from osteopetrosis and cleidocranial dysostosis in order to diagnose it in individuals of a younger age.

The aims of this case report were to show the clinical, radiographic, and diagnostic features, as well as the cephalometric characteristics of pycnodysostosis in comparison with Turkish cephalometric norms. (Eur J Dent 2012;6:454-456)

Key words: Cleidocranial dysostosis; diagnosis; osteopetrosis; pycnodysostosis

\section{INTRODUCTION}

Pycnodysostosis was first described in 1962 by Maroteaux and Lamy. It is a rare autosomalrecessive disorder in which osteoclast dysfunction

\footnotetext{
1 Department of Orthodontics, Faculty of Dentistry, Kirikkale University, Kırıkkale, TURKIYE

2 Department of Periodontology, Faculty of Dentistry, Kırıkkale University, Kırıkkale, TURKIYE

${ }^{3}$ Department of Orthodontics, Faculty of Dentistry, Erciyes University, Kayseri, TURKIYE

1

Corresponding author: Dr. Hasan Kamak Kirikkale Universitesi, Dishekimligi Fakultesi, Ortodonti AD. Kırıkkale, TURKIYE

Tel: +903182244927

Fax: +903182250685

Email address: hkamak@agmail.com
}

causes osteosclerosis. The name derives from the Greek words pycnos (dense), dys (defective), and ostosis (bone). The disorder is also known as Toulouse-Lautrec syndrome, named after the French artist who suffered from pycnodysostosis. ${ }^{1}$ The principal characteristics of this disorder are short stature, cranial dysplasia, clavicular dysplasia, total/partial dysplasia of the terminal phalanges, obtused mandibular gonial angle, and generally increased bone density. ${ }^{2}$ Intraoral features include persistence of deciduous teeth with premature or delayed eruption of the permanent teeth, which can cause crowding. In addition, very poor oral hygiene, periodontal disease, tooth misalignment, enamel hypoplasia, and a grooved palate have 
been observed.3,4 Dental abnormalities such as hypoplasia of the enamel, obliterated pulp chambers, and hypercementosis are some of the most striking features of this anomaly. ${ }^{5}$

In this case report, we aim to present the case of a girl with pycnodysostosis and show the clinical, radiographic, and diagnostic features, as well as the cephalometric characteristics of this anomaly, to help clinicians and professionals to diagnose it in younger individuals.

\section{CASE REPORT}

An 18-year-old girl was referred for orthodontic treatment to the Department of Orthodontics, Faculty of Dentistry, Atatürk University, Erzurum, Turkey. In terms of general health, the patient had glass-bone disease. In the clinical examination, the forehead was prominent with some bossing, the nose was beaked (Figure 1), and the eyes had blue sclera. There was no significant pallor or lymphadenopathy. The weight and standing height of the patient were $28 \mathrm{~kg}$ and $126 \mathrm{~cm}$, respectively. The hands showed the striking feature of shortened fingers. Although the structure of the nails was normal, the length was short (Figure 2).

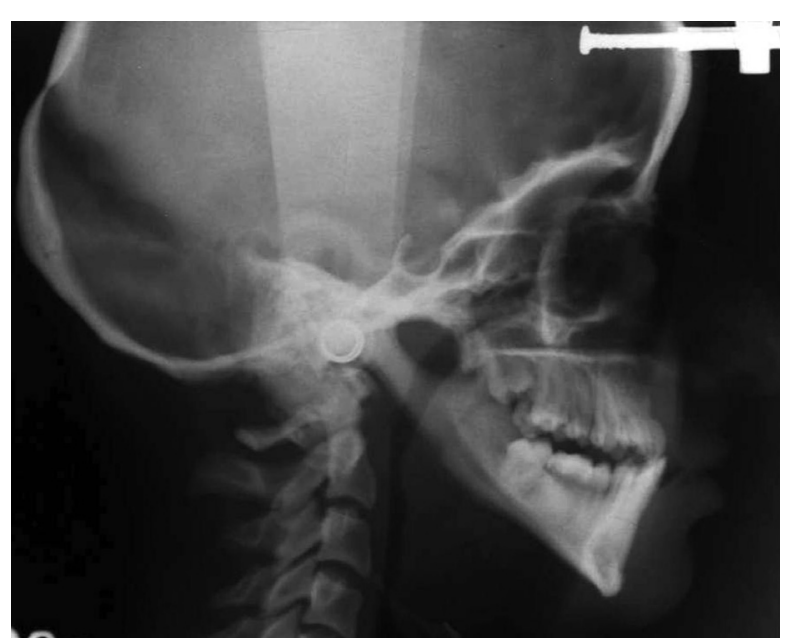

Figure 1. Lateral cephalometric radiograph showing an open lambdoid suture, hypoplastic maxilla, obtused mandibular gonial angle, and posterior open bite
Examination of the mouth revealed a narrow and grooved palate. Additionally, dental crowding, hypoplastic teeth, bilateral open bite, and crossbite were observed (Figure 3). Radiographical examination revealed increased density and dysplasia of the terminal phalanges of the fingers (Figure 4). The maxillary left lateral incisor, second molar, and all third molars were congenitally absent, and the right maxillary lateral incisor was peg shaped. In addition, both the maxilla and mandible were hypoplastic (Figures 3, 5, and 6). The lambdoid suture was open, and the mandibular angle was obtuse with prognathism (Figures 1 and 5).

Cephalometric measurements of the patient with pycnodysostosis were analyzed and compared with Gazilerli norms. ${ }^{6}$ The most common observations from the cephalometric analysis were retropositioned maxilla (SNA 68.0 ) and mandible (SNB $71.5^{\circ}$ ) with a Class III skeletal pattern (ANB -3.5) of malocclusion. However, from a clinical perspective, the soft tissue profile did not reflect the Class III skeletal pattern. In addition, an obtused mandibular gonial angle (Ar-Go-Me 163.0), hyperdivergent mandibular growth (SN-GoGn 54.0'), reduced anterior and posterior facial height ( $\mathrm{N}-\mathrm{Me}$ $106.0 \mathrm{~mm}$, S-Go $60.0 \mathrm{~mm}$ ), a maxillary transverse deficiency, and a proclined mandibular incisor were present, but the maxillary incisor inclination was normal (Table 1).

The periodontal examination of the patient consisted of recordings of visible plaque, oral hygiene, gingival bleeding, probing depth, and clinical attachment level. The average plaque score was 2 and gingival bleeding score was 1. Periodontal pockets and clinical attachment loss were absent. Changes in gingival color and contour, edema, and very poor oral hygiene were present. Because of these findings, the patient's periodontal disease was diagnosed as plaque-induced gingivitis and was treated (Figure 3).

Table 1. Cephalometric measurements of the patient compared with Turkish cephalometric norms. ${ }^{6}$

\begin{tabular}{lcc}
\hline Measurements & Patient's & Gazilerli Norms \\
\hline SNA (0) & 68 & $81.0 \pm 3.5$ \\
SNB (0) & 71.5 & $78.0 \pm 3.5$ \\
ANB (0) & -3.5 & $3.0 \pm 2.0$ \\
SN-GoGn (0) & 54 & $31.0 \pm 5.0$ \\
Ar-Go-Me (0) & 163 & $120.5 \pm 6.0$ \\
N-Me (mm) & 106 & $121.5 \pm 6.5$ \\
S-Go (mm) & 60 & $83.0 \pm 6.0$ \\
Mx1-SN (0) & 105 & $99.0 \pm 6.0$ \\
Md1-MP (0) & 105 & $96.0 \pm 7.5$ \\
\hline
\end{tabular}


The patient was also examined by a geneticist, who performed genetic tests. Finally, the patient was diagnosed with pycnodysostosis. The patient's family history revealed that her parents were normal.

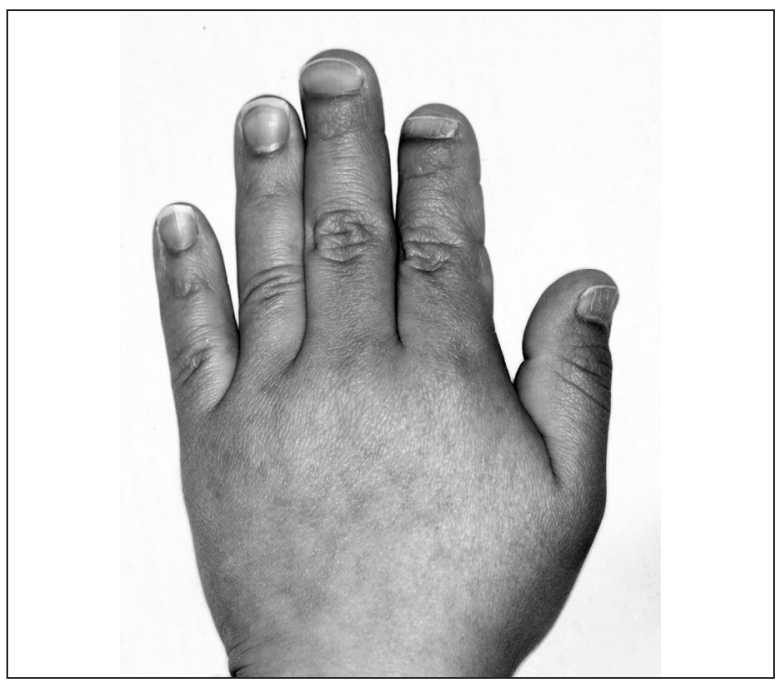

Figure 2. A photograph of the hand showing the striking feature of shortened fingers

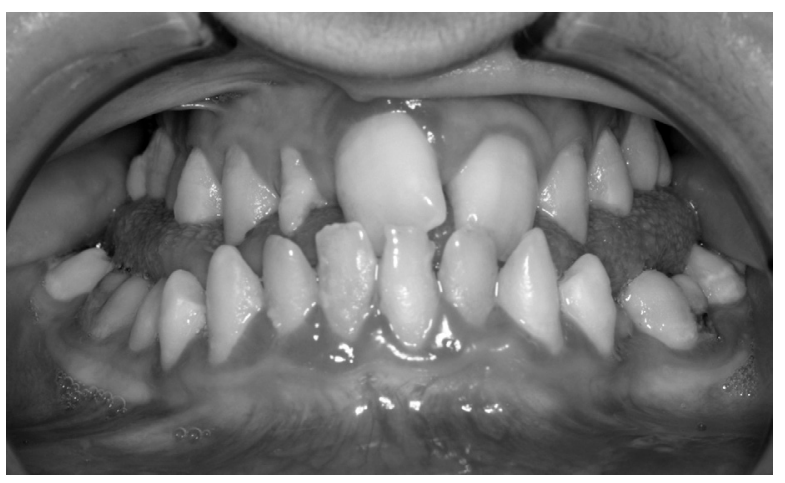

Figure 3. The intraoral frontal photograph showing dental crowding, Class III dentition, posterior open bite, periodontal disease, and dental caries

\section{DISCUSSION}

Pycnodysostosis is an autosomal-recessive disorder in which osteoclast dysfunction causes osteosclerosis. ${ }^{7}$ The incidence of this anomaly is estimated to be 1.7 per 1 million births. ${ }^{3}$ It is believed that the first case description of pycnodysostosis was in 1923 by Montanari; however, Maroteaux and Lamy defined the characteristic features of pycnodysostosis in $1962 .^{3}$ General features include short stature (less than $150 \mathrm{~cm}$ ), generalized diffuse osteosclerosis with a tendency for fracture after minimal trauma, and hypoplastic clavicles. ${ }^{3.4}$ Cranial and maxillofacial features include prominent eyes with blue sclerae, relative proptosis, beaked nose, frontoparietal bossing, open fontanelles and cranial sutures, hypoplastic paranasal sinuses, and an obtuse mandibular gonial angle, often with relative prognathism..$^{3,4,8}$ These findings were in agreement with the present case report. Norholt et al $^{9}$ stated that these

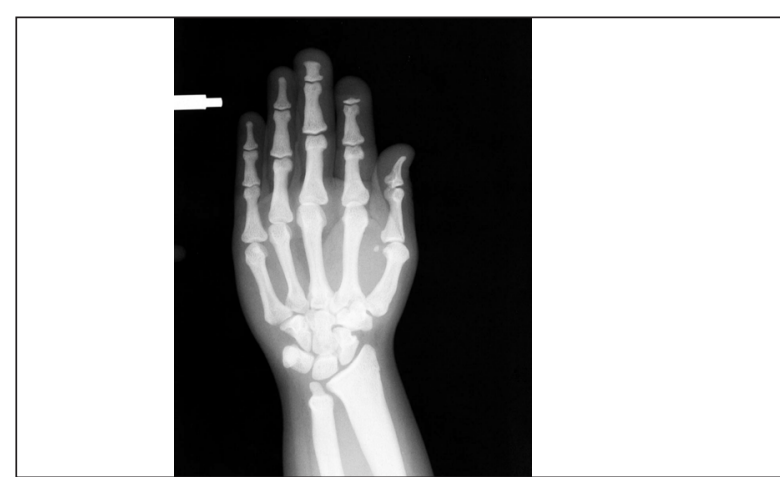

Figure 4. The hand-wrist radiograph showing shortened terminal distal phalanges

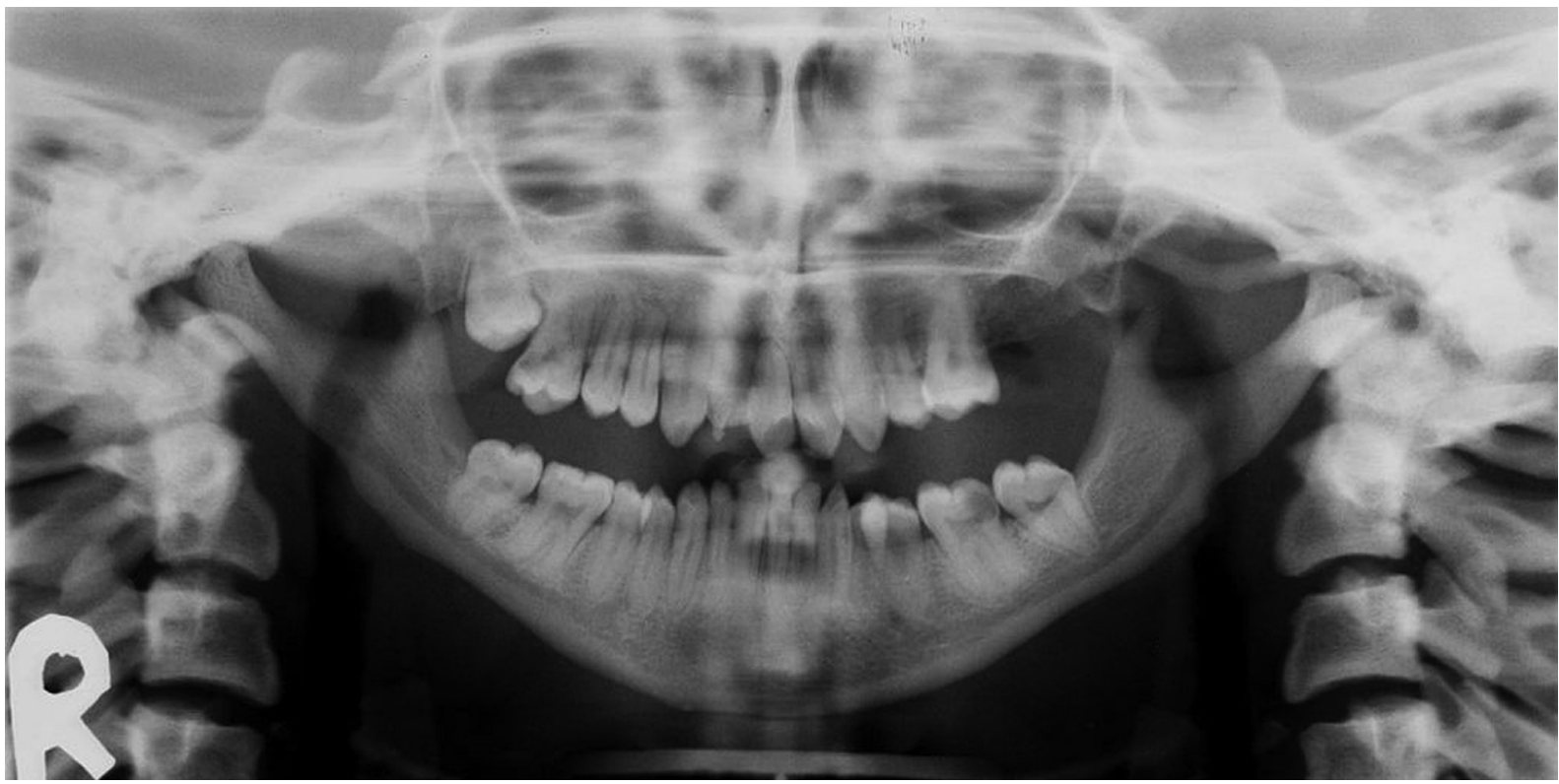

Figure 5. A panoramic radiograph showing a small mandible, hypodontia, and malpositioned dentition 
patients often present a Class III dentition owing to the maxillary hypoplasia.

Intraoral features include persistence of deciduous teeth with premature or delayed eruption of the permanent teeth, which can cause crowding. In addition, tooth misalignment, enamel hypoplasia, and a grooved palate have been observed. ${ }^{3,4}$ Dental abnormalities such as hypoplasia of the enamel, obliterated pulp chambers, and hypercementosis are some of the most striking features in this anomaly. Additionally, dental crowding associated with extensive caries and periodontitis is frequently observed. ${ }^{5}$ Dental crowding impedes correct oral hygiene for the patients with pycnodysostosis. In the present study, although persistence of deciduous teeth was not observed, the congenital absence of many permanent teeth and peg-shaped lateral incisors were observed.

Many studies in literature have reported on clinical and radiological findings, ${ }^{10-13}$ cephalometric measurements, $, 14,15$ and diagnostic features ${ }^{16-18}$ associated with this syndrome. However, only the present study has incorporated all of these factors and included cephalometric measurements of the patient compared with Turkish cephalometric norms.

In the present cephalometric findings, a hypoplastic maxilla and mandible were observed, evidenced by SNA, SNB, and Go-Me measurements,

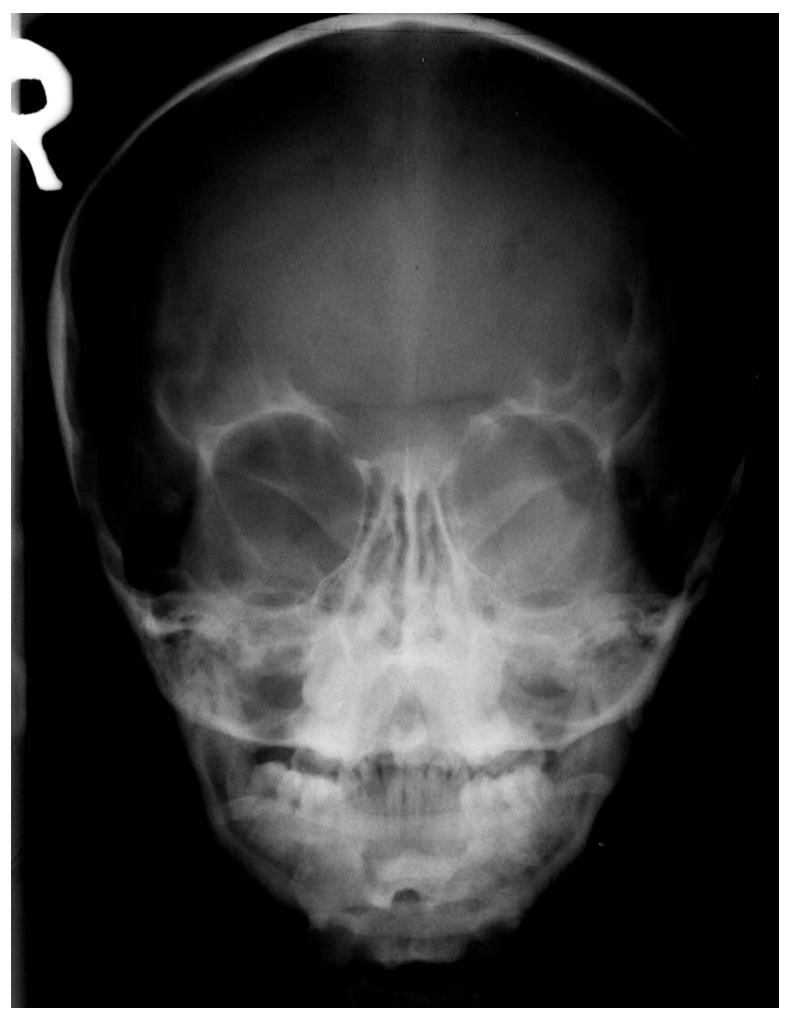

Figure 6. A posteroanterior radiograph showing the hypoplastic maxilla and man dible respectively. It is believed that the maxilla would be more involved in the development of the significantly undesirable sagittal skeletal pattern of these subjects. These findings associated with decreased SNA and ANB angles may strongly influence the Class III pattern of malocclusion. A highly retropositioned maxilla may be a possible explanation for this observed and previously described numeric factor, ${ }^{4,15}$ which was identified as a negative ANB angle in the present case. Interestingly, the soft tissue profile was able to mask the intensity of the radiographically observed skeletal Class III malocclusion.

In addition, this case showed a vertical growth with increased SN-GoMe and FH-MP angles, with an important influence from a deficient posterior facial height (S-Go). The N-Me measurements, representing the total anterior facial height, were also significantly reduced. Findings similar to these have been recently reported by Fonteles et $\mathrm{al}^{15}$ in Brazil.

Some features of pycnodysostosis are similar to the more common disorders of osteopetrosis and cleidocranial dysostosis. ${ }^{7}$ Therefore, pycnodysostosis must be distinguished from osteopetrosis and cleidocranial dysostosis. Emami-Ahari et $\mathrm{al}^{17}$ and $\mathrm{Yeo}^{18}$ reported the comprehensive diagnostic features of these anomalies. Osteopetrosis is a dominant trait, which is characterized by generalized increased bone density. The malignant forms are recessive, in which there is severe aplastic anemia caused by the obliteration of the medullary canals and early death. ${ }^{19}$ Cleidocranial dysostosis is an inherited autosomal dominant disorder and is characterized by a usually normal stature and normal texture of bones except for an increased density of the base of the skull in some cases. ${ }^{20}$

Pycnodysostosis is an autosomal recessive anomaly and affected individuals have characteristic facies, beaked nose, blue sclera, short stature, aplasia of the digits, generalized increase in the density of bones even though not sufficient to obliterate medullary canals or cranial passages, abnormal dentition, and bone healing at a normal rate with normal blood findings. ${ }^{17}$ In pycnodysostosis and cleidocranial dysostosis, exposed fontanelles and cranial sutures are observed at an advanced age, ${ }^{21}$ although in the present case the glass-bone disease was also observed-a bone abnormality rarely seen in pycnodysostosis.

There is no specific treatment for this anomaly and the current treatment is only supportive. Rec- 
ommendations or information about the effective and reliable orthodontic treatment of children or young adults with pycnodysostosis is not available in the literature. ${ }^{15}$ Orthodontic and orthopedic movements are dependent on osteoclastic activity, bone resorption, and remodeling capacities. ${ }^{15}$ Although some authors propose early treatment using orthodontic methods, others argue that the lack of bone remodeling would impede satisfactory results; hence, planned extractions would be more suitable. ${ }^{10}$ Tooth extraction in patients with pycnodysostosis is carried out during surgery as atraumatically as possible to reduce the risk of fracture, especially in the mandible. ${ }^{5}$ However, post-extraction osteomyelitis may develop because of the increased bone density. ${ }^{22}$ Treatment of osteomyelitis in individuals with pycnodysostosis is difficult and may lead to large resections. . $^{3,9}$ Norholt et al9 have defended the orthognathic correction by using a distraction osteogenesis technique. However, the most important orthopedic problem for orthognathic correction is the high infection rates and the recurrent pathological fracture of bones owing to the limited quality and vascularity of the sclerotic bone. ${ }^{3}$

\section{CONCLUSION}

Patients with pycnodysostosis and glass-bone disease characterized by osteoclast dysfunction, fragile bone, craniofacial defects, severe malocclusion, and dental anomalies should be carefully examined and risk factors should be determined while planning treatment. The risks should be explained to patients and surgeons, and the treatment of these patients should be decided taking into consideration all the factors. Frequent visits to the dentist would be suitable for these patients to emphasize the importance of extraordinary oral hygiene to prevent dental decay and periodontal disease.

\section{REFERENCES}

1. Helms CA. Metabolic bone disease. In: Brant WE, Helms CA, eds. Fundamentals of Diagnostic Radiology. Philadelphia: Lippincott Williams \& Wilkins 1999:1049-1059.

2. Maroteaux P, Lamy M. [Pyknodysostosis.]. Presse Med 1962;70:999-1002.

3. Bathi RJ, Masur VN. Pyknodysostosis--a report of two cases with a brief review of the literature. Int J Oral Maxillofac Surg 2000;29:439-442.
4. Hunt NP, Cunningham SJ, Adnan N, Harris M. The dental, craniofacial, and biochemical features of pyknodysostosis: a report of three new cases. J Oral Maxillofac Surg 1998;56:497-504.

5. Landa S, Esteban S, Montes E, Santamaria J, Vitoria A, Santolaya JM. Maxillofacial alterations in a family with pycnodysostosis. Med Oral 2000;5:169-176.

6. Gazilerli U. The Steiner norms between 13-16 years old Turkish children with the normal occlusion on the region of Ankara. (Master Thesis) Ankara University, Turkey 1976.

7. Beighton P, Horan F, Hamersma H. A review of the osteopetroses. Postgrad Med J 1977;53:507-516.

8. Glass RB, Fernbach SK, Norton KI, Choi PS, Naidich TP. The infant skull: a vault of information. Radiographics 2004;24:507-522.

9. Norholt SE, Bjerregaard J, Mosekilde L. Maxillary distraction osteogenesis in a patient with pycnodysostosis: a case report. J Oral Maxillofac Surg 2004;62:1037-1040.

10. O'Connell AC, Brennan MT, Francomano CA. Pycnodysostosis: orofacial manifestations in two pediatric patients. $\mathrm{Pe}$ diatr Dent 1998;20:204-207.

11. Soliman AT, Ramadan MA, Sherif A, Aziz Bedair ES, Rizk MM. Pycnodysostosis: clinical, radiologic, and endocrine evaluation and linear growth after growth hormone therapy. Metabolism 2001;50:905-911.

12. Jones CM, Rennie JS, Blinkhorn AS. Pycnodysostosis. A review of reported dental abnormalities and a report of the dental findings in two cases. Br Dent $J$ 1988;164:218-220.

13. Muto T, Michiya H, Taira H, Murase H, Kanazawa M. Pycnodysostosis. Report of a case and review of the Japanese literature, with emphasis on oral and maxillofacial findings. Oral Surg Oral Med Oral Pathol 1991;72:449-455.

14. Muto T, Yamazaki A, Takeda S, Tsuji Y, Shibata T. Pharyngeal narrowing as a common feature in pycnodysostosis-a cephalometric study. Int J Oral Maxillofac Surg 2005;34:680685.

15. Fonteles CS, Chaves CM, Jr., Da Silveira A, Soares EC, Couto JL, de Azevedo Mde F. Cephalometric characteristics and dentofacial abnormalities of pycnodysostosis: report of four cases from Brazil. Oral Surg Oral Med Oral Pathol Oral Radiol Endod 2007;104:e83-90.

16. Wolpowitz A, Matisonn A. A comparative study of pycnodysostosis, cleidocranial dysostosis, osteopetrosis and acroosteolysis. S Afr Med J 1974;48:1011-1018.

17. Emami-Ahari Z, Zarabi M, Javid B. Pycnodysostosis. J Bone Joint Surg Br 1969;51:307-312.

18. Yeo TC. Pycnodysostosis--report of a case. Singapore Med J 1988;29:611-616. 
19. Kneal E, Sante LR. Osteopetrosis (marble bones); report of a case with special reference to early roentgenologic and pathological findings. AMA Am J Dis Child 1951;81:693-707.

20. Forland M. Cleidocranial dysostosis. A review of the syndrome and report of a sporadic case, with herediatary transmission. Am J Med 1962;33:792-799.

21. Fratzl-Zelman N, Valenta A, Roschger P, Nader A, Gelb BD, Fratzl P, Klaushofer K. Decreased bone turnover and deterioration of bone structure in two cases of pycnodysostosis. J Clin Endocrinol Metab 2004;89:1538-1547.

22. Iwu CO. Bilateral osteomyelitis of the mandible in pycnodysostosis. A case report. Int J Oral Maxillofac Surg $1991 ; 20: 71-72$. 